\title{
Toward the early diagnosis of the HELLP syndrome in the community hospital
}

\author{
BENJAMIN P. KELCH, D.O. \\ Dublin, Ohio \\ MICHAEL L. NOWAK, D.O. \\ Columbus, Ohio
}

The acronym HELLP

applies to a syndrome of hemolysis (microangiopathic hemolytic anemia), elevated liver enzyme values, and low platelet count (thrombocytopenia). The disease may occur in association with severe preeclampsia and eclampsia, but it may also occur with mild to moderate hypertension in pregnancy. The initial diagnosis is often incorrect and thought to be unrelated to pregnancy. Four cases that illustrate features of this syndrome are reported. An approach to the patient is suggested on the basis of a view of the pathogenesis of this syndrome.

The triad of hemolysis, elevated liver enzyme values, and a low platelet count was given the acronym HELLP syndrome by Weinstein ${ }^{1}$ in 1982 . This triad was originally described in association with preeclampsia and eclampsia and is characterized by a microangiopathic hemolytic anemia, derangements of liver enzymes, and thrombocytopenia. It is important for the clinician to be aware of its existence, because it is often misdiagnosed initially, and many of the patients presenting with the HELLP syndrome are referred to other specialists for the diagnosis and treatment of an ailment thought to be unrelated to pregnancy. ${ }^{1-3}$ Indeed, in 2 of our 4 cases, nonobstetric consultants were asked to evaluate these patients. The patient in case 1 was initially thought to have recurrent nephrolithiasis, and the woman in case 3 was thought to have active peptic ulcer disease.

\section{Report of cases}

\section{Case 1}

A 32-year-old white woman, gravida I, para-0-0-0-0, was admitted in early labor at term. She complained of blurred vision and right flank pain. Her past medical history was positive for nephrolithiasis. Two weeks prior to admission she had been noted to have mild, pregnancyinduced hypertension (PIH) of $140 / 90 \mathrm{~mm}$. Hg, and she was sent home for bed rest. She was somewhat noncompliant with this program, and on admission her blood pressure was $160 / 90 \mathrm{~mm}$. Hg. During labor the blood pressure was consistently elevated, and the deep tendon reflexes were $4 / 4$ bilaterally. Fourteen hours after admission, a low-transverse cesarean section was performed for dysfunctional labor and ominous fetal heart rate patterns. A 3,089-gm., viable male neonate with Apgar scores of 8 and 9 was delivered.

Prenatal laboratory work revealed a hemoglobin $(\mathrm{Hb})$ value of $12.5 \mathrm{gm} . / \mathrm{dl}$., hematocrit (Hct) reading of 38.2 percent, and platelet (Plt) count of $324,000 / \mathrm{cu}$. $\mathrm{mm}$. The admission values were as follows: $\mathrm{Hb}, 13.1 \mathrm{gm} . / \mathrm{dl}$., Hct; 38.2 percent; and Plt, 203,000/cu. $\mathrm{mm}$. By the time of cesarean section, the $\mathrm{Hb}$ value was $12.0 \mathrm{gm}$./dl., the Hct reading was 35 percent, and the Plt count was $63,000 / \mathrm{cu}$. $\mathrm{mm}$. The admission prothrombin time (PT) and partial thromboplastin times (PTT) were normal, as was the fibrinogen level, and fibrin degradation products (FDPs) were nondetectable.

Other admission laboratory values were as follows: blood urea nitrogen (BUN), $16 \mathrm{mg}$./dl.; creatinine (Cr), 0.9 mg./dl.; hepatitis B surface antigen (HBsAg) and antihepatitis core antigen ( $a n t i-H B c A g)$, negative; direct and indirect Coombs' tests, negative. After cesarean section, a biochemical screen (SMA-20) revealed the following values: alkaline phosphatase (ALK PO4), 287 (normal 30-115) I.U.; serum glutamic-oxaloacetic transaminase (SGOT), 450 (normal 0-41) I.U.; serum glutamic-pyruvic transaminase (SGPT), 456 (normal 0-45) I.U.; lactate dehydrogenase (LDH), 1,257 (normal 60-200) I.U.; total bilirubin (TB), 0.9 (normal 0.2-1.2) mg./dl.; and uric acid (UA), 7.5 (normal female value, 2.2-7.7) mg./dl. Her postoperative $\mathrm{Hb}$ level and Hct reading were $11.0 \mathrm{gm} . / \mathrm{dl}$. and 32.6 percent, respectively, with a Plt count of 55,000 / cu. $\mathrm{mm}$.

Hypertension complicated her postoperative course, (blood pressure, 170/120 mm./Hg), and she was treated with intravenous hydralazine. A central scotoma secondary to retinal detachment occurred on the third postoperative day. After surgery, her liver function test values fell, and they were nearly normal at discharge on the seventh postoperative day. At that time the $\mathrm{Hb}$ value was $13.4 \mathrm{gm} . / \mathrm{dl}$., the Hct reading was 37.7 percent, and the Plt count was $141,000 / \mathrm{cu}$. mm. The PT, PTT, and fibrinogen values remained normal throughout the entire course of her hospital stay. Her laboratory data are 
summarized in Tables 1 and 2 .

\section{Case 2}

A 20-year-old white woman, gravida I, para-0-0-0-0, was admitted at term with a complaint of nausea, vomiting, and epigastric pain for 24 hours prior to admission. Her blood pressure had been noted as $136 / 98 \mathrm{~mm}$. Hg during an office visit, and she had been sent home for bed rest. The patient was initially seen in the Labor and Delivery area of the hospital 6 hours prior to admission with epigastric pain and was sent home with a diagnosis of viral gastroenteritis. On admission, the blood pressure was $162 / 110 \mathrm{~mm}$. Hg. Six hours after admission, a low-transverse cesarean section was performed because of failed induction, and a 3,004-gm., viable male neonate with Apgar scores of 9 and 9 was delivered.

Prenatal laboratory work revealed the following values: $\mathrm{Hb}, 13.5 \mathrm{gm} . / \mathrm{dl}$.,; Hct, 38.7 percent; and Plt, $258,000 / \mathrm{cu}$. $\mathrm{mm}$. On admission, the $\mathrm{Hb}$ concentration was $11.2 \mathrm{gm} . / \mathrm{dl}$., the Hct reading was 31 percent, and the Plt count was $60,000 / \mathrm{cu}$. mm. The admission PT, PTT, and fibrinogen values were normal and FDPs were nondetectable. Other admission laboratory values revealed a BUN of 13.0 and $\mathrm{Cr}$ of 0.9 . HBsAg and anti-HBcAg tests gave negative results, as did the direct and indirect Coombs' tests. Admission SMA-20 revealed the following values: ALK PO4, 154 I.U.; SGOT, 228 I.U.; SGPT, 277 I.U.; LDH, 654 I.U.; TB, $2.2 \mathrm{mg} . / \mathrm{dl}$; and UA, $8.4 \mathrm{mg} . / \mathrm{dl}$.

The patient's postoperative course was complicated by hypotension, persistent tachycardia, and a falling hemoglobin level. She was monitored for 48 hours in the intensive care unit, where she received a total of 6 units of packed red cells, 3 units of fresh frozen plasma, and 15 units of platelets, which resulted in stabilization of her vital signs. Postoperatively, the liver function test values fell. She was discharged on the sixth postoperative day with the following laboratory values: $\mathrm{Hb}, 10.8 \mathrm{gm} . / \mathrm{dl}$; Hct, 29.4 percent; and Plt, 133,000/cu. mm. PT, PTT, and fibrinogen values were normal throughout her hospital stay. Pertinent laboratory values are summarized in Tables 1 and 2 .

\section{Case 3}

A 34-year-old Hispanic woman, gravida II, para-1-0-0-1, was admitted at 31 weeks' gestation with a chief complaint of nausea, vomiting, and epigastric pain radiating to the right upper quadrant, back, and scapular area for 3 hours prior to admission. The past medical history was positive for peptic ulcer disease and proctitis, with no history of hypertension during pregnancy. The blood pressure was $160 / 105 \mathrm{~mm}$. Hg on admission, and, because of her presenting complaints, surgical consultation was obtained. Shortly thereafter the patient had a grand mal seizure and was placed on a magnesium sulfate infusion and underwent a classic cesarean section. A 1,742-gm., viable male neonate with Apgar scores of 3 and 7 and an estimated gestational age of 31.5 weeks was delivered. The infant was placed in the neonatal intensive care unit and subsequently did well. At the time of cesarean section the patient was noted to have a partial placental abruption.

Prenatal laboratory values were as follows: $\mathrm{Hb}, 12.7$ gm,/dl.; Het, 37.6 percent; and Plt, 238,000/ cu. mm. On admission, the $\mathrm{Hb}$ level was $12.8 \mathrm{gm} . / \mathrm{dl}$., the Hct reading was 37.6 percent, and the Plt count was $165,000 / \mathrm{cu}$. mm. The admission PT was 11.0 seconds, with a control value of 12.5 seconds. PTT was 25.1 seconds (normal, 18.0-35.0), the fibrinogen value was $335 \mathrm{mg} . / \mathrm{dl}$., (normal, 200-400 mg./dl.), , and FDPs were detectable at a level $>10 \mathrm{mg} . / \mathrm{dl}$. but $<40 \mathrm{mg}$./dl. Other laboratory values were as follows: BUN, $17 \mathrm{mg} . / \mathrm{dl}$.; Cr, $0.8 \mathrm{mg} . / \mathrm{dl}$; $\mathrm{HBsAg}$ and anti-HBcAg tests, negative; and direct and indirect Coombs' tests,

TABLE 1. HEMATOLOGIC PROFILE.

\begin{tabular}{|c|c|c|c|c|c|c|c|c|c|c|}
\hline \multirow[b]{2}{*}{$\begin{array}{l}\text { Case } \\
\text { no. }\end{array}$} & \multicolumn{2}{|c|}{ Prenatal values } & \multirow[b]{2}{*}{$\begin{array}{l}\text { Platelet } \\
\text { count } \\
\text { (no./cu.mm.) }\end{array}$} & \multirow[b]{2}{*}{$\begin{array}{l}\text { Hemoglobin } \\
\text { (gm./dl.) }\end{array}$} & \multicolumn{2}{|c|}{ Lowest values } & \multicolumn{4}{|c|}{ Longest time } \\
\hline & $\begin{array}{l}\text { Hemoglobin } \\
\text { (gm./dl.) }\end{array}$ & $\begin{array}{l}\text { Hematocrit } \\
\text { (ml./dl.) }\end{array}$ & & & $\begin{array}{l}\text { Hematocrit } \\
\text { (ml./dl.) }\end{array}$ & $\begin{array}{l}\text { Platelet } \\
\text { count } \\
\text { (no./cu.mm.) }\end{array}$ & $\begin{array}{l}\text { Fibri- } \\
\text { nogen } \\
\text { (mg./dl.) }\end{array}$ & $\begin{array}{l}\text { PT } \\
\text { (sec.) }\end{array}$ & $\begin{array}{l}\text { PTT } \\
\text { (sec.) }\end{array}$ & $\begin{array}{l}\text { Abnormal } \\
\text { peri- } \\
\text { pheral } \\
\text { smear }\end{array}$ \\
\hline 1 & 12.5 & 38.2 & 324,000 & 9.4 & 27.2 & 56,000 & 320 & 11.7 & 24.7 & Yes \\
\hline 2 & 13.5 & 38.7 & 258,000 & 8.4 & 24.3 & 41,000 & 320 & 12.4 & 28.0 & Yes \\
\hline 3 & 12.7 & 37.6 & 238,000 & 6.5 & 18.5 & 50,000 & 186 & 14.9 & 36.0 & Yes \\
\hline 4 & Not avai & lable & & 7.1 & 20.8 & 36,000 & 240 & 13.5 & 35.0 & Yes \\
\hline
\end{tabular}

TABLE 2. HEPATIC AND RENAL FUNCTION PROFILE.

\begin{tabular}{|c|c|c|c|c|c|c|c|c|}
\hline \multirow[b]{2}{*}{$\begin{array}{l}\text { Case } \\
\text { no. }\end{array}$} & \multicolumn{5}{|c|}{ Maximum values } & \multicolumn{3}{|c|}{ Admission values } \\
\hline & $\begin{array}{l}\text { ALK PO4 } \\
\text { (I.U.) }\end{array}$ & $\begin{array}{l}\text { SGOT } \\
\text { (I.U.) }\end{array}$ & $\begin{array}{l}\text { SGPT } \\
\text { (I.U.) }\end{array}$ & $\begin{array}{l}\text { LDH } \\
\text { (I.U.) }\end{array}$ & $\begin{array}{c}\text { TB } \\
\text { (mg./dl.) }\end{array}$ & $\begin{array}{l}\text { BUN } \\
\text { (mg./dl.) }\end{array}$ & $\begin{array}{c}\mathrm{Cr} \\
(\mathrm{mg} . / \mathrm{dl} .)\end{array}$ & $\begin{array}{c}\text { UA } \\
\text { (mg./dl.) }\end{array}$ \\
\hline 1 & 287 & 450 & 456 & 1,257 & 1.3 & 16.0 & 0.9 & 7.5 \\
\hline 2 & 154 & 228 & 227 & 654 & 3.4 & 13.0 & 0.9 & 8.4 \\
\hline 3 & 545 & 2,658 & 2,350 & 3,880 & 14.1 & 17.0 & 0.8 & 6.7 \\
\hline 4 & 296 & 672 & 432 & 1,458 & 3.6 & 21.0 & 1.0 & 4.6 \\
\hline
\end{tabular}

Key: ALK PO4 = alkaline phosphatase; SGOT = serum glutamic-oxaloacetic transaminase; SGPT = serum glutamic-pyruvic transaminase; $\mathrm{LDH}=$ lactic dehydragenase $\mathrm{TB}=$ Total bilirubin; $\mathrm{BUN}=$ blood urea nitrogen; $\mathrm{Cr}=$ creatinine; and $\mathrm{UA}=\mathrm{uric}$ acid. 
negative. Admission SMA-20 revealed the following values: ALK PO4, 161 I.U.; SGOT, 129 I.U.; SGPT, 109 I.U.; LDH, 295 I.U.; TB, $0.2 \mathrm{mg} . / \mathrm{dl}$.; and UA, $6.7 \mathrm{mg}$./dl.

Postoperatively, the patient continued to manifest ongoing hemolysis with falling $\mathrm{Hb}$ and $\mathrm{Hct}$ values and Plt count. She had prolongation of the PT and PTT, a decrease in the fibrinogen levels, and increasing levels of FDPs, which were consistent with disseminated intravascular coagulation. Packed erythrocytes, fresh frozen plasma, cryoprecipitate, and platelet transfusion were used to correct her coagulopathy. Her postoperative course was complicated by adult respiratory distress syndrome, disseminated intravascular coagulation, and acute tubular necrosis, which required prolonged mechanical ventilation, hemodynamic monitoring via a pulmonary artery catheter, and hemodialysis on several occasions. She was discharged on the eighteenth postoperative day with all laboratory parameters returning to normal. The extreme derangements of metabolic function are summarized in Tables 1 and 2.

\section{Case 4}

A 28-year-old, psychotic black woman, gravida I, para-0-0-0-0, was admitted at 35 weeks' gestation with a complaint of nausea and vomiting for 5 hours prior to admission and rupture of membranes for 7 hours before admission. Her blood pressure was $176 / 120 \mathrm{~mm}$. Hg. The patient had signed out of the hospital 48 hours prior to this admission after refusing therapy for mild PIH. Her past medical history was unremarkable. Seven hours after admission, a low-transverse cesarean section was performed after failed induction, and a 2,693-gm., viable male infant with Apgar scores of 7 and 8 was delivered.

No prenatal laboratory data were available for this patient because she had received no prenatal care. On admission, the $\mathrm{Hb}$ level was $10.5 \mathrm{gm} . / \mathrm{dl}$., the Hct reading was 34.4 percent, and the Plt count was $62,000 / \mathrm{cu}$. mm. The admission PT, PTT, and fibrinogen values were normal, and FDPs were detectable at values $>10 \mathrm{mg}$./dl. but $<40 \mathrm{mg}$./dl. Other admission laboratory results included a BUN value of $21.0 \mathrm{mg} . / \mathrm{dl}$. and a $\mathrm{Cr}$ level of $1.0 \mathrm{mg} . / \mathrm{dl}$. $\mathrm{HBsAg}$ and anti-HBcAg tests yielded negative results, as did the direct and indirect Coombs' tests. Admission SMA-20 revealed the following values: ALK PO4, 296 I.U.; SGOT, 475 I.U.; SGPT, 462 I.U.; LDH, 541 I.U.; TB, $0.7 \mathrm{mg} . / \mathrm{dl}$; and UA, $4.6 \mathrm{mg}$. $/ \mathrm{dl}$.

The patient's postoperative course was complicated by tachycardia and hypotension. She sustained a cardiopulmonary arrest 24 hours after cesarean section. This was thought to be secondary to cardiac tamponade, with the patient responding to emergency pericardiocentesis and standard advanced life-support protocols. During the 48 hours after cardiac arrest, she remained comatose; however, on the third day she began responding to deep, painful stimuli. Her neurologic status continued to improve over the next several days, to the point where she would open her eyes in response to verbal command. At this time her family requested that she be transferred to the local university medical center, and the patient has been lost to follow up.

On the day of her transfer, her eighth hospital day at this institution, she had the following laboratory values: $\mathrm{Hb}, 11.9$ gm./dl.; Hct, 34.3 percent; and Plt, 473,000/cu. $\mathrm{mm}$. The ALK PO4, SGOT, SGPT, LDH, TB, and UA values were all within normal limits. Pertinent laboratory data are summarized in Tables 1 and 2.

\section{Discussion}

Although the acronym HELLP syndrome was attached to the triad of hemolysis, elevated liver enzyme values, and a low platelet count by Weinstein ${ }^{1}$ in 1982 in a series of 29 cases, there have been case reports in the English-language literature as early as 1954, when Pritchard and associates ${ }^{4}$ described 3 cases. Between 1954 and 1976, there were 28 cases reported in the English-language literature by various authors, including Goodlin, ${ }^{5,6} \mathrm{McKay},{ }^{7}$ and Killam $^{2}$ and their coworkers. Beecham and associates ${ }^{8}$ reported 5 cases; however, they documented hemolysis, elevated liver enzymes, and low platelets in only 4 . Experience with additional cases has been reported recently by MacKenna, ${ }^{9}$ Øian, ${ }^{3}$ Clark, ${ }^{10}$ Mabie, ${ }^{11}$ Egley, ${ }^{12}$ and Goodlin ${ }^{13}$ and their coauthors. Because the 4 cases reported in this paper all clearly had the HELLP syndrome, we would like to add them to the literature.

Weinstein ${ }^{1}$ described the HELLP syndrome as occurring in association with severe preeclampsia and eclampsia, as have several other authors. ${ }^{4-7}$ Our experience parallels that of Killam and associates $^{2}$ in that the disease has been associated not with severe preeclampsia, but only with mild to moderate changes in blood pressure. After discussing pathogenesis and treatment options, we will use this observation to postulate a new approach to viewing the pathogenesis of the HELLP syndrome, and to explain why it is often misdiagnosed initially.

\section{Pathogenic mechanisms}

Numerous theories have been proposed to explain the abnormalities associated with the HELLP syndrome. The most attractive explanation is that the underlying mechanism is disseminated intravascular coagulation (DIC). The sine qua non of diagnosis in DIC is the demonstration of fibrin deposits in the microvasculature of multiple organs. This is obviously impractical in the clinical practice of medicine; hence, clinical criteria should be used. McKay ${ }^{7}$ listed these criteria as follows: (1) the demonstration of consumptive coagulopathy; (2) the presence of a microangiopathic hemolytic anemia (MAHA); (3) the occurrence of a constellation of clinical signs and symptoms, including overt bleeding, hypotension, nausea, vomiting, petechiae, oliguria, anuria, seizures, hematuria, dyspnea, and cyanosis; and (4) a favorable response to a therapeutic trial of heparin, as evidenced by 
clinical or hematologic improvement.

The mechanism of hemolysis in MAHA has been elucidated by Brain and coauthors. ${ }^{14}$ Abnormalities of the peripheral smear are characteristic of patients with MAHA. Representative blood smears showing evidence of erythrocyte fragmentation from cases 3 and 4 are depicted in Figures 1 and 2. Platelet consumption has also been shown to occur in association with DIC in preeclampsia. ${ }^{15,16}$ The abnormalities of liver function can be explained by the deposition of fibrin in the hepatic microvasculature as part of the multiple organ involvement in DIC. Most of the articles cited in the literature review describe varying degrees of subcapsular hemorrhage or hematoma at the time of cesarean section in patients with the HELLP syndrome. Therefore, DIC could account for the hemolysis, elevated liver enzyme values, and low platelet count seen in this syndrome.

The argument against DIC being the etiology in the HELLP syndrome is really twofold. The first argument is that all of the clinical criteria for the diagnosis of DIC should be applicable to a patient population before they are labeled as having DIC. It is evident in both our series and the other reported series that a number of these patients have normal PT, PTT, and fibrinogen levels and lack overt bleeding complications in spite of their profound thrombocytopenia. It is difficult to make a case for the presence of a consumptive coagulopathy in the absence of clinically overt bleeding. The clinical picture of DIC that developed in case 3 can be explained on the basis of the patient's partial placental abruption found at the time of cesarean section. Could "subclinical" DIC be occurring in these patients? This concept has been addressed by Greer and coauthors. ${ }^{17}$
The second argument against DIC being the etiology involves viewing the components of the syndrome as separate pathologic occurrences within the spectrum of preeclampsia and eclampsia. Brain and associates ${ }^{14}$ have described the presence of MAHA in eclampsia. Early platelet consumption in preeclampsia has also been documented..$^{18}$ In addition, immunofluorescent evidence of hepatic fibrinogen deposits in preeclamptic women in the absence of overt DIC has been presented. ${ }^{19}$ Fibrinogen in the hepatic sinusoids could cause local stasis with resultant passive congestion and areas of local ischemia. The passive congestion accounts for the right upper quadrant and/or epigastric pain, while the local ischemia and resultant hepatocellular necrosis account for elevated liver enzymes. The elevated $\mathrm{LDH}$ and TB values can be a result of either hepatic dysfunction or hemolysis. Classically in hemolysis, the LDH 1 isoenzyme value is elevated and the indirect bilirubin is elevated out of proportion to the direct bilirubin. Neither LDH isoenzyme analysis or bilirubin fractionation were performed on any of our patients.

Goodlin ${ }^{5,6}$ offered yet another theory of the pathogenesis of the HELLP syndrome based upon a reduction in blood volume in the preeclamptic patient. He stated the view that there is an inappropriate response in the preeclamptic woman such that blood volume is not expanded in proportion to the increase in the size of the uterus. The consistently reduced blood volume causes generalized vasoconstriction. The consequences are analogous to shock-decreased organ perfusion accounting for the elevated liver enzymes and small vessel spasm leading to the microangiopathic disordersthrombocytopenia and hemolysis.
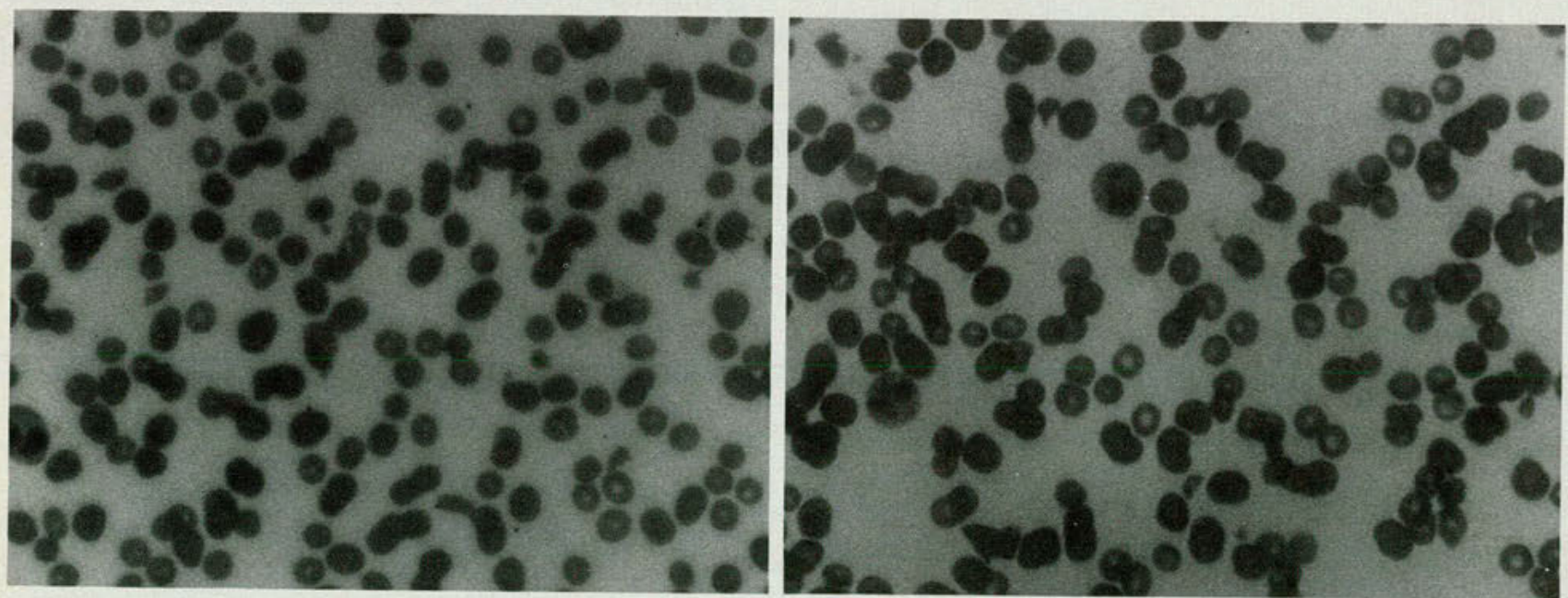

Fig. 1 (Case 3). Peripheral smear showing schistocytes-small fragmented erythrocytes characteristic of microangiopathic hemolytic anemia. Fig. 2 (Case 4). Peripheral smear documenting the presence of erythrocyte fragmentation. 


\section{Treatment}

Several methods of treatment are available to patients with the HELLP syndrome- expedient delivery of the infant, replacement of platelets and clotting factors if the patient manifests bleeding tendencies, expansion of intravascular volume, heparin therapy, and the use of steroids and/or antiplatelet drugs. The entire subject of the HELLP syndrome is very controversial, and, until the underlying pathogenesis is understood, treatment will be empiric rather than rational.

We will review the various treatment modalities reported in the literature and discuss some theoretical arguments in their usage. Weinstein, ${ }^{1}$ who has reported the largest series of patients with the HELLP syndrome, stated, "In my opinion, conservative management in the patient with the HELLP symptom sic may be detrimental to maternal survival. Aggressive treatment is indicated, with delivery to occur in the most expedious manner."

Indeed, the case reports of Killam, ${ }^{2} \varnothing \mathrm{ian},{ }^{3}$ McKay, ${ }^{7}$, Beecham, ${ }^{8}$ and Goodlin, ${ }^{5,6}$ and their associates show that the fulminating course of the patients' disease was apparently reversed in the majority of the cases by delivery of the infant. Hypertension was controlled in most cases with intravenous hydralazine infusion, and a large number of patients were placed on magnesium sulfate infusion. The logical conclusion is that prompt delivery of the infant should be the cornerstone of management. The following discussion of other treatment modalities is offered purely from the theoretical standpoint.

Steroids are often used in the treatment of the "acquired" thrombocytopenias, such as idiopathic thrombocytopenic purpura (ITP) and thrombotic thrombocytopenic purpura (TTP). It was probably for this reason that Pritchard and coworkers ${ }^{4}$ used ACTH infusion in two of their patients. Their conclusion, however, was that ACTH was of little value in these instances.

In some cases of DIC in which platelets are thought to make an exclusive contribution to thrombus formation (for example, TTP), antiplatelet drugs have been utilized. ${ }^{20,21}$ None of the patients presented in the literature was treated with antiplatelet therapy.

If reduced blood volume is indeed the underlying mechanism of the HELLP syndrome, then agents directed at expanding blood volume such as low molecular-weight dextran, plasma, or albumin have a theoretical advantage. Goodlin ${ }^{13}$ treated several of his patients in this manner with seemingly good results. In addition, Goodlin ${ }^{13}$ suggested that bed rest increased plasma volume by mobilization of extracellular fluid. The major criticism of his work is that it was not a controlled clinical trial.

If we assume that DIC is the pathogenic mechanism in the HELLP syndrome, then heparin therapy and clotting factor replacement are of theoretical value. In the setting of serious bleeding, we assume a failure of the hemostatic mechanism due to depletion of coagulation factors. Replacement of these factors with cryoprecipitate, fresh frozen plasma, fibrinogen concentrate, or fresh whole blood would be indicated. There are no data in the literature to support the concept that replacing these factors in patients is "feeding the fire" of consumptive coagulopathy. ${ }^{22}$ Many of the patients received these products perioperatively or postsurgically, including two of our patients, without untoward effects.

Heparin therapy is yet another modality that has a theoretical advantage in the treatment of the HELLP syndrome, if it is assumed that a consumptive coagulopathic process is the mechanism of disease. Heparin's use in this situation is aimed at producing controlled anticoagulation in an attempt to interrupt the consumption of coagulation factors. The employment of heparin seems paradoxic in the face of an overtly hemorrhaging patient; however, its use in DIC is as logical as its administration in a patient who has any kind of localized arterial or venous thrombosis. ${ }^{22} \mathrm{McKay}^{7}$ described the use of heparin in 2 cases of HELLP syndrome and reached no conclusion as to the benefit of therapy. Beecham and coauthors ${ }^{8}$ reported the use of heparin in 3 cases. In 1 case apparently dramatic results were obtained, whereas for the other 2 patients, heparin therapy was discontinued because of hepatic rupture in 1 and delivery of a stillborn infant in the other. Killam and associates ${ }^{2}$ reported the use of heparin in one patient. They made a cogent argument against its use, finding that it brought about no decrease in neonatal deaths or maternal complications. Furthermore, it seems unwise to heparinize a patient prior to performing major surgery if cesarean section is indicated. Indeed, Weinstein ${ }^{1}$ reported a cesarean rate of 76 percent in his patient population.

\section{Approach to the patient}

We would like to present an approach to the patient with the HELLP syndrome as we view the underlying pathogenesis. We begin by considering the HELLP syndrome as a spectrum of disease within pregnancy-induced hypertension. If we can extrapolate from Weinstein's ${ }^{1}$ experience, it seems as if he views the spectrum of disease as follows: Pregnancy-Mild PIH-Severe PIH-HELLP syndrome-DIC-Death. From our limited experience 
in this area, we propose that the clinician should view the spectrum of the disease as follows: Pregnancy-Mild PIH-HELLP syndrome-Severe PIH-DIC-Death.

If this method of thinking is adopted, it alerts the clinician to suspect the HELLP syndrome as the most serious consequence early in the natural history of the disease process. Early recognition implies diagnosis at the "earliest possible stage," which, in our experience and in the experience of Killam and associates, ${ }^{2}$ was usually associated with mild to moderate change in blood pressure. We are of the opinion that if one waits until full blown $\mathrm{PIH}$ or frank eclampsia is present, serious complications threaten both mother and fetus.

In the past, physicians have been reluctant to order extensive blood testing on obstetric patients, especially those who present with vague symptoms and apparently minor illness (nausea, vomiting, epigastric pain, and a slight increase in blood pressure), such as the patients with the HELLP syndrome initially experienced. A high index of suspicion of the HELLP syndrome must be maintained in any pregnant patient who presents with vague complaints of nausea, vomiting, epigastric or right upper quadrant pain, and even mild elevation of blood pressure. Indeed, the initial blood pressure should be compared to prenatal values where possible, and a rise of $30 \mathrm{~mm}$. Hg systolic pressure and/or $15 \mathrm{~mm}$. Hg diastolic pressure should be considered significant. In this setting more extensive laboratory testing can be accomplished, including platelet counts and evaluation of liver function. We believe that once the diagnosis is made, immediate termination of pregnancy is vital to maternal survival. After reviewing all of the cases reported in the literature, it seems that once the diagnosis of HELLP syndrome is made, the immediate termination of the pregnancy is vital to maternal survival.

\section{Summary}

Four illustrative cases of HELLP syndrome are presented, with clinical manifestations, laboratory data, and therapeutic modalities. The current literature is reviewed and a theory on the pathogenesis of the HELLP syndrome is offered.

Appreciation is expressed to Narciso Albarracin, M.D., of the Department of Pathology and Ms. Jackie Woo of the Department of Training and Education, Doctors Hospital, Columbus, Ohio, for their expert technical assistance in preparing pathologic and tabular materials for this paper; to John B. Reed, D.O., for reviewing this manuscript; and to Frank J. Dono, D.O., for permission to review one of his patient's records.

1. Weinstein, L.: Syndrome of hemolysis, elevated liver enzymes, and low platelet count. A severe consequence of hypertension in pregnancy. Am J Obstet Gynecol 142:159-67, 15 Jan 82

2. Killam, A.P., et al.: Pregnancy-induced hypertension complicated by acute liver disease and disseminated intravascular coagulation. Five case reports. Am J Obstet Gynecol 123:823-8, 15 Dec 75

3. Øian, P., Maltau, J.M., and Abyholm, T.: HELLP syndrome-a serious complication of hypertension in pregnancy. Acta Obstet Gynecol Scand 63:727-9, 1984

4. Pritchard, J.A., et al.: Intravascular hemolysis, thrombocytopenia and other hematologic abnormalities associated with severe toxemia of pregnancy. N Engl J Med 250:89-98, 21 Jan 54

5. Goodlin, R.C.: Severe pre-eclampsia. Another great imitator. Am J Obstet Gynecol 125:747-53, 15 Jul 76

6. Goodlin, R.C., Cotton, D.B., and Haesslein, H.C.: Severe edema-proteinuria-hypertension gestosis. Am J Obstet Gynecol 132:595-8, 15 Nov 78

7. McKay, D.G.: Hematologic evidence of disseminated intravascular coagulation in eclampsia. Obstet Gynecol Surv 27:399-417, 1972

8. Beecham, J.B., Watson, W.J., and Clapp, J.F., III.: Eclampsia, preeclampsia, and disseminated intravascular coagulation. Obstet Gynecol 43:576-85, Apr 74

9. MacKenna, J., Dover, N.L., and Brame, R.G.: Pre-eclampsia associated with hemolysis, elevated liver enzymes, and low platelet-an obstetrical emergency? Obstet Gynecol 62:751-4, Dec 83

10. Clark, S.L.: Antepartum reversal of hematologic abnormalities associated with the HELLP syndrome. A report of three cases. J Reprod Med 31:70-2, Jan 86

11. Mabie, B.C., et al.: Severe hypoglycemia associated with the HELLP syndrome (letter). Am J Obstet Gynecol 154:211-2, Jan 86

12. Egley, C.C., Gutilph, J., and Bowes, W.A., Jr.: Am J Obstet Gynecol 152:576-7, 1 Jul 85

13. Goodlin, R.C., and Holdt, D.: Impending gestasis. Obstet Gynecol 58:743-5, Dec 81

14. Brain, M.C., Dacie, J.V., and Hourihane, D. O'B.: Microangiopathic haemolytic anemia. The possible role of vascular lesions in pathogenesis. Br J Haematol 8:358-74, 1962

15. Howie, P.W., Prentice, C.R., and McNichol, G.P.: Coagulation, fibrinolysis and platelet function in pre-eclampsia, essential hypertension and placental insufficiency. Br J Obstet Gynaecol Br Commonw 78:992-1003, Nov 71

16. Howie, P.W., et al.: Use of coagulation tests to predict the clinical progress of pre-eclampsia. Lancet 2:323-5, 14 Aug 76

17. Greer, I.A., Cameron, A.D., and Walker, J.J.: HELLP syndrome. Pathologic entity or technical inadequacy (letter). Am J Obstet Gynecol 152:113-4, 1 May 85

18. Redman, CWG, Bonnar, J., and Beilin, L.: Early platelet consumption in pre-eclampsia. Br Med J 1:467-9, 25 Feb 78

19. Arias, F, and Mancilla-Jimenez, R.: Hepatic fibrinogen deposits in pre-eclampsia. Immunofluorescent evidence. N Engl J Med 295:578-82, 9 Sep 76

20. Neame, P.B., et al.: Thrombotic thrombocytopenic purpura. Report of a case with disseminated intravascular platelet aggregation. Blood 42:805-14, Nov 73

21. Harker, L.A., and Slichter, S.J.: Platelet and fibrinogen consumption in man. N Engl J Med 287:999-1005, 16 Nov 72

22. Sharp, A.A.: Diagnosis and management of disseminated intravascular coagulation. Br Med Bull 33:265-72, Sep 77

Accepted for publication in April 1986. Updating, as necessary, has been done by the authors.

Dr. Kelch is a resident in internal medicine at Doctors Hospital, Columbus, Ohio. Dean L. Colwell, D.O., was resident trainer when the paper was written. Dr. Nowak is attending physician, Department of Obstetrics and Gynecology, Doctors Hospital.

Dr. Kelch, 3208 Heatherside Drive, Dublin, Ohio 43017. 